\title{
Supply chain disruption assessment based on the newsvendor model
}

\author{
Yisong $\mathrm{Li}^{1}$, Xiaofei Chen ${ }^{2}, \mathrm{Lu} \mathrm{Jia}^{3}$ \\ ${ }^{1,3}$ School of Economics and Management, Beijing Jiaotong University (China) \\ ${ }^{2}$ Department of Mechanical and Industrial Engineering, University of Toronto (Canada) \\ ysli@,bjtu.edu.cn,xiaofei.chen@utoronto.ca,10125150@,bjtu.edu.cn
}

\section{Abstract:}

Purpose: This paper focuses on supply chain disruption assessment.

Design/methodology/approach: Newsvendor Model.

Findings: As both cost and income principle will be taken into account in supply chain disruption assessment, we proposed in this paper: (1) the problem of supply chain disruption assessment is the trade-off problem. (2) the generic single period - newsvendor model can be used for capturing the critical point, which in tradition model stands for the demarcation point of profit but in this paper is the least costs considering disruption costs and expected revenues.

Research limitations/implications: single period - newsvendor model.

Practical implications: we give an example for test the effectiveness of this method.

Originality/value: to research supply chain risk in a new approach, that is: supply chain risk has both cost and profit. So we can assess it with trade-off method.

Keywords: supply chain disruption, risk assessment, newsvendor model. 


\section{Introduction}

Nowadays, facing the complicated and variable commercial environment as well as have been doing efforts in lean management for quicker response and lower cost, supply chain are tend to vulnerable and liable to affected by various risks. In order to managing the supply chain risk, the twin areas of risk identification and risk assessment are playing the basic and the most important part of the theoretical foundation and practical value field.

Wakolbinger and Cruz (2009) summarized that the risks supply chain faced can be classified into two types: supply-demand coordination risks and disruption risks. Moreover, the disruption risks are the most vital and most notably type because the fact that disruption can bring about huge losses and prevention cost. Zhang (2011) emphasized disruptions and figured out that cost-income principle must be followed when build the fortification models, that is to say, the model concerned not only the cost of disruption, but also the expected cost of lost revenues.

This paper aims at supply chain disruption assessment, analyzing two types of costs, which can be related to disruption risks. The two costs respectively stand for two kinds of attitudes towards risks- risk averse and risk appetite. Based on newsvendor model and its trade-off idea, the paper establishes one model can weigh the two costs, namely the two risk attitudes, and therefore get the optimal assessment solution. In the end, by means of the example, we can see that, it is useful to ranking risks concerning.

\section{Literature Review}

As it is the foundation on assessment, a lot of literatures have focused on identifying the risks of supply chain, Manuj and Mentzer (2008) categorized the risk in supply chain by means of conducting an extensive literature review. They present a generic framework for the risk in global supply chains into the following broad classes: supply risks, operational risks, demand risks, security risks, macro risks, policy risks, competitive risks, and resource risks. This categorization highlights the generic business aspects of risk, and was widely accepted in the research of supply chain risk management (SCRM).

The general approach of supply chain risk management (SCRM) starts with the identification of business objectives, and then links the performance goals with the risks. Ritchie and Brindley (2004) gives an example to shows that the identifying risk can lead to increasing its visibility in the performance evaluation process, and this can leads to risk minimization strategies that can contribute to performance gains.

The identification of supply chain risk gives us a clue of assessment of the risk in a supply chain. 
In the assessment of the risk in a supply chain, Harland, Brenchley and Walker (2003). provided a standard formula for the quantitative definition of supply chain risk. That is:

$$
\text { Risk }=P \times L
$$

Where Risk is the assessment result; $\mathrm{P}$ means the probability or possibility; L means the loss of consequences.

Now, most of the researches take two types variables ( $P$ and $L)$ into consideration.

The literature on assessment of the supply chain risk usually defines risk in purely negative terms, and leading to undesired results or consequences. Some model of SCRM are based on this aspect. Ding (2004) provided a fuzzy factor technique to evaluate risks; Ericsson developed a series of tools named ERMET (Ericsson Risk Management Evaluation); Meng (2009) built an evaluation model based on grey relational analysis combining the fuzzy assessment.

But, SCRM not only takes negative but also takes positive to the supply chain. Christopher (2006) gave an integrated definitions developed by others that "the management of supply chain risks through coordination or collaboration among the supply chain partners so to ensure profitability and continuity".

We can infer from the description that the objectives of supply chain risk management (SCRM) fall into two aspects: the one is to enhance profit, the other is to lower the disruptions existing supply chain.

Moreover, to reduce the disruptions means must to pay more costs for precautions and controls in a supply chain, but at the same time, it also means that protect profit will ask costcontrol.

The perspective of this view can be resulted in the tradeoff problem. And it leads to the new direction of taking the newsvendor model into account.

Traditionally, newsvendor models is manly refer to the vendor of the supply chain, and mostly assumed to be risk-neutral and insensitive to profit variations with the objective of expected profit maximization or expected cost minimization. Recently, the vulnerability and risks in the supply chains remind the managers of the tradeoff expected profit for downside protection against possible losses (Xu \& Li, 2010). In this respect, Werner \& Peter $(2007,2008,2011)$ specially promoted this issues. They formulated the newsvendor model of the same kind that tradeoff between service level (target value) and resulting losses by the target. Qin, Wang, Vakharia, Chen and Seref (2011) enriched the theory by considering the attitude of decisionmaker towards the risks, devoted to the analysis newsvendor model with various risk 
preferences, including, but not limited to, risk-averse and risk-seeking preferences. Besides, they also reviewed and directed the future research in newsvendor problem, modeled how the buyer's risk profile moderates the newsvendor order quantity decision. Anastasios, Dimitrios and Eleftherios (2011) develop a newsvendor model for both risk neutral and risk-averse decision-makers and can be applicable for different types of disruptions related among others to the supply of raw materials, the production process, and the distribution system, as well as security breaches and natural disaster.

To sum up, the new direction of SCRM and newsvendor problem will be of tradeoff value target and losses may resulting in. Risk attitude of decision-maker is also a crucial point to be regarded.

\section{Newsvendor model for supply chain disruption assessment}

The idea of traditional newsvendor model is that: when the demand is Stochastic, the managers expect to achieve profit maximization or loss minimization by optimum order quantity. In fact, the order quantity is a ratio based on a "critical point", which makes the optimal probability of target function. In addition, traditional newsvendor managers bear the risk neutral attitude towards the risks.

There is the probabilities assessment in the evaluation of supply chain risks. No matter by means of qualitative expert evaluation method or quantitative methods emerging continuously in the academic circles, it is expected to make a best assessment of supply chain risks. By virtue of thought of newsvendor model, it is a feasible approach to get the risks assessment on the foundation of an optimal "critical point ratio" weighing against costs, and the target function is to make the risks prevention cost and risks response cost minimum. Besides, the weight of two costs, at the same time, is also the weight of two attitudes-risk averse and risk appetite.

\subsection{Model foundation}

This model considers risks probability as a continuous variable. To assess the probability of a risk occurring, it introduces two types of costs to weigh against. That is called opportunity cost and disruption cost in this model. The former is the cost spends on preventing risks from happening, and the latter is the loss to response the consequences after risks occur.

Assume a certain risk's probability is stochastic and obeys a known distribution.

Evaluate an occurrence probability of the risk is $P$. 
- If $\mathrm{P}$ is higher than the actual probability. That is to say, risk averse decision overestimates the risk giving rise to an overdone prevention and emergence action, which generates opportunity cost.

- If $\mathrm{P}$ is lower than the actual probability. That is to say, risk appetite decision underestimates the risk binging about a potential disruption point in supply chains, which a liable to generate disruption cost. Assume a certain risk is named $\mathrm{N}_{\mathrm{i}}$. Its actual occurrence probability is $r$, obeying a distribution with density function $\phi(r)$, namely

$$
\int_{0}^{r} \phi(r) d r=1
$$

In one risk assessment process, its calculating probability is $\mathrm{p}$.

In order to get the optimal solution $\mathrm{p}^{*}$, define the two concerned cost in the first place.

\section{Opportunity Cost L}

When risks are overestimated $(p \geq r)$, opportunity cost happens and the loss is:

$(p-r) \cdot L$, so its expectation value is:

$$
\int_{0}^{p} L \cdot(p-r) \phi(r) d r
$$

\section{Disruption Cost $C_{1}$}

When risks are underestimated $(p<r)$, disruption cost happens and its loss is:

$(r-p) \cdot C_{1}$, so its expectation value is:

$$
\int_{p}^{\infty} C_{1}(r-p) \phi(r) d r
$$

\subsection{The optimal decision}

When a risk $\mathrm{N}_{i}$ and its calculated probability is $\mathrm{p}$, combining the mentioned above(1) and(2), the total expectation losses are:

$$
E[C(p)]=L \int_{0}^{p}(p-r) \phi(r) d r+C_{1} \int_{p}^{\infty}(r-p) \phi(r) d r
$$

Target function is $\min E[C(P)]$.

Here follows the differentiation method inference process of newsvendor model: 
When $p$ is continuous variable, $E[C(P)]$ is continuous function about $p$.

$$
\begin{aligned}
& \text { So, } \frac{d E[C(p)]}{d p}=\frac{d}{d p}\left[L \int_{0}^{p}(p-r) \phi(r) d r+C_{1} \int_{p}^{\infty}(r-p) \phi(r) d r\right] \\
&=L \int_{0}^{p} \phi(r) d r-C_{1} \int_{p}^{\infty} \phi(r) d r
\end{aligned}
$$

Let

$$
\frac{d E[C(p)]}{d p}=0
$$

If

$$
\varphi(r)=\int_{0}^{p} \phi(r) d r
$$

Then

$$
L \cdot \varphi(p)-C_{1} \cdot[1-\varphi(p)]=0
$$

and

$$
\varphi(p)=\frac{C_{1}}{L+C_{1}}
$$

Therefore, $\mathrm{p}$ is solved from the arithmetic expression above, and be denoted as $\mathrm{P} *$, then $\mathrm{P} *$ is the stationary point of $E[C(P)]$.

And because

$$
\frac{d^{2} E[C(P)]}{d p^{2}}=L \phi(p)+C_{1} \phi(p)>0
$$

It is clear that $p^{*}$ is the limited minimum point of $E[C(P)]$, minimum point of the model.

\subsection{Model analysis}

It can be inferred from the optimal decision:

$$
\varphi\left(p^{*}\right)=\frac{C_{1}}{L+C_{1}}
$$


That the optimal assessment result towards some certain risks comprehensively affected by followings:

\section{Opportunity cost L}

This part of cost in reality reflects that manager is risk averse attitude, which means the loss of potential profits.

Because of the averse of risk, manager takes vigorous prevention and emergence measures so as to be more defensive to disruptions in supply chain. Correspondingly, the overprotection needs more cost input, so the opportunity cost is come into being.

This kind of cost is inversely proportional to the result $\mathrm{p}^{*}$. The higher some certain kinds of risks' opportunity cost is, the lower their optimal assessment probability is.

\section{Disruption $\operatorname{cost} C_{1}$}

When manager's preference towards risk is risk appetite, the cost input to prevent risk from occurring is much more than the risk averse manager. But in contrast, there are more risk events happen, and can bring more disruption cost.

The optimal risk assessment will be a tradeoff between the two types of costs.

\section{Density function}

This is the general rule of the occurrence of risk. And generally normal distribution is the most universal used one. Its density function can be showed as following:

$$
\begin{aligned}
& \phi(r)=\frac{1}{\sigma \sqrt{2 \pi}} e^{-\frac{(r-\mu)^{2}}{2 \sigma^{2}}}, \\
& -\infty<r<+\infty
\end{aligned}
$$

Where $\mu$ is mean value, and $\sigma$ is standard deviation.

\section{Example}

\subsection{Background and risks identification}

An enterprise wants to rebuild its supply chain network, in order to improve its performance and competitiveness. But as its limited resources and funds, it is necessary to evaluating the costs and benefits of each risk in its supply chain, and to rebuild the supply chain network from the most importance parts. 


\begin{tabular}{|l|l|l|}
\hline Identification & Details & Symbol \\
& lack of capacity & $\mathrm{N}_{1}$ \\
\cline { 2 - 3 } Supply risk & technology retardation & $\mathrm{N}_{2}$ \\
\cline { 2 - 3 } & Poor credit & $\mathrm{N}_{3}$ \\
\cline { 2 - 3 } & traffic inconvenience & $\mathrm{N}_{4}$ \\
\cline { 2 - 3 } & natural disaster & $\mathrm{N}_{5}$ \\
\hline \multirow{5}{*}{ Product risk } & customer churn & $\mathrm{N}_{6}$ \\
\cline { 2 - 3 } & lower prediction & $\mathrm{N}_{7}$ \\
\cline { 2 - 3 } & demand fluctuations & $\mathrm{N}_{8}$ \\
\hline \multirow{5}{*}{ Information risk risk } & manufacturing interrupt & $\mathrm{N}_{9}$ \\
\cline { 2 - 3 } & product diversification & $\mathrm{N}_{10}$ \\
\cline { 2 - 3 } & product substitution & $\mathrm{N}_{11}$ \\
\cline { 2 - 3 } & stockpiling & $\mathrm{N}_{12}$ \\
\hline & system paralysis & $\mathrm{N}_{13}$ \\
\cline { 2 - 3 } & communication outage & $\mathrm{N}_{14}$ \\
\cline { 2 - 3 } & poor information & $\mathrm{N}_{15}$ \\
\hline \multirow{5}{*}{ Finance risk } & exchange fluctuations & $\mathrm{N}_{16}$ \\
\cline { 2 - 3 } & supplier bankruptcy & $\mathrm{N}_{17}$ \\
\cline { 2 - 3 } & customer bankruptcy & $\mathrm{N}_{18}$ \\
\hline
\end{tabular}

Table 1. Supply Chain Risks Identification

According to the identification of the supply chain risk, the enterprise classifies its risks into: supply risk, manufacture risk, demand risk, information risk and finance risk. Moreover, the enterprise analysis the above risks of supply chain in detail as the table 1 . These are the factors of the supply chain network.

\begin{tabular}{|c|c|c|c|c|c|c|}
\hline \multirow{2}{*}{$\begin{array}{c}\text { The table } 2 \text { is parameters } \\
\text { demonstration used in } \\
\text { newsvendor model to assess } \\
\text { supply chain } \\
\text { disruption.identification }\end{array}$} & \multirow[b]{2}{*}{ Details } & \multirow[b]{2}{*}{ Number } & \multicolumn{2}{|c|}{ Cost } & \multicolumn{2}{|c|}{ Profit } \\
\hline & & & $\begin{array}{l}\text { Prevent } \\
\text { cost }\end{array}$ & $\begin{array}{l}\text { Interrupt } \\
\text { cost }\end{array}$ & $\begin{array}{l}\text { Risk } \\
\text { obedient } \\
\text { earnings }\end{array}$ & $\begin{array}{l}\text { Opportunity } \\
\text { cost }\end{array}$ \\
\hline \multirow{5}{*}{ Supply risk } & lack of capacity & $\mathrm{N}_{1}$ & $\mathrm{C}_{01}$ & $\mathrm{C}_{11}$ & $\mathrm{~L}_{01}$ & $\mathrm{~L}_{11}$ \\
\hline & technology retardation & $\mathrm{N}_{2}$ & $\mathrm{C}_{02}$ & $\mathrm{C}_{12}$ & $\mathrm{~L}_{02}$ & $\mathrm{~L}_{12}$ \\
\hline & poor credit & $\mathrm{N}_{3}$ & $\mathrm{C}_{03}$ & $\mathrm{C}_{13}$ & $\mathrm{~L}_{03}$ & $\mathrm{~L}_{13}$ \\
\hline & traffic inconvenience & $\mathrm{N}_{4}$ & $\mathrm{C}_{04}$ & $\mathrm{C}_{14}$ & $\mathrm{~L}_{04}$ & $\mathrm{~L}_{14}$ \\
\hline & natural disaster & $\mathrm{N}_{5}$ & $\mathrm{C}_{05}$ & $\mathrm{C}_{15}$ & $\mathrm{~L}_{05}$ & $\mathrm{~L}_{15}$ \\
\hline \multirow{3}{*}{ Demand risk } & customer churn & $\mathrm{N}_{6}$ & $\mathrm{C}_{06}$ & $\mathrm{C}_{16}$ & $\mathrm{~L}_{06}$ & $\mathrm{~L}_{16}$ \\
\hline & lower prediction & $\mathrm{N}_{7}$ & $\mathrm{C}_{07}$ & $\mathrm{C}_{17}$ & $\mathrm{~L}_{07}$ & $\mathrm{~L}_{17}$ \\
\hline & demand fluctuations & $\mathrm{N}_{8}$ & $\mathrm{C}_{08}$ & $\mathrm{C}_{18}$ & $\mathrm{~L}_{08}$ & $\mathrm{~L}_{18}$ \\
\hline \multirow{4}{*}{ Product risk } & manufacturing interrupt & $\mathrm{N}_{9}$ & $\mathrm{C}_{09}$ & $\mathrm{C}_{19}$ & $\mathrm{~L}_{09}$ & $L_{19}$ \\
\hline & product diversification & $\mathrm{N}_{10}$ & $\mathrm{C}_{010}$ & $C_{110}$ & $\mathrm{~L}_{010}$ & $L_{110}$ \\
\hline & product substitution & $\mathrm{N}_{11}$ & $\mathrm{C}_{011}$ & $C_{111}$ & $\mathrm{~L}_{011}$ & $\mathrm{~L}_{111}$ \\
\hline & stockpiling & $\mathrm{N}_{12}$ & $\mathrm{C}_{012}$ & $\mathrm{C}_{112}$ & $\mathrm{~L}_{012}$ & $\mathrm{~L}_{112}$ \\
\hline \multirow{3}{*}{ Information risk } & system paralysis & $\mathrm{N}_{13}$ & $\mathrm{C}_{013}$ & $\mathrm{C}_{113}$ & $\mathrm{~L}_{013}$ & $\mathrm{~L}_{113}$ \\
\hline & communication outage & $\mathrm{N}_{14}$ & $\mathrm{C}_{014}$ & $\mathrm{C}_{114}$ & $\mathrm{~L}_{014}$ & $\mathrm{~L}_{114}$ \\
\hline & poor information & $\mathrm{N}_{15}$ & $\mathrm{C}_{015}$ & $\mathrm{C}_{115}$ & $\mathrm{~L}_{015}$ & $\mathrm{~L}_{115}$ \\
\hline \multirow{3}{*}{ Finance risk } & exchange fluctuations & $\mathrm{N}_{16}$ & $\mathrm{C}_{016}$ & $C_{116}$ & $L_{016}$ & $\mathrm{~L}_{116}$ \\
\hline & supplier bankruptcy & $\mathrm{N}_{17}$ & $\mathrm{C}_{017}$ & $\mathrm{C}_{117}$ & $\mathrm{~L}_{017}$ & $\mathrm{~L}_{117}$ \\
\hline & customer bankruptcy & $\mathrm{N}_{18}$ & $\mathrm{C}_{018}$ & $\mathrm{C}_{118}$ & $\mathrm{~L}_{018}$ & $\mathrm{~L}_{118}$ \\
\hline
\end{tabular}

Table 2. Parameters Demonstration

\subsection{The trade-off of the costs and profits}

We need evaluating the costs and profits according to the factors in table 1 of the Supply Chain Risks Identification, before we made trade-off analysis of the supply chain risk when rebuild the supply chain network. 
In the front of supply chain risk, manager must assess the probability of each factors and its cost, which are prevent cost and interrupt cost. And if manager is obedient to the supply chain risks, he can obtain revenue from it, which are risk obedient earnings and opportunity cost. When manager is obedient to the supply chain risk, he has to take risk of interrupt of supply chain.

\subsection{Simulation}

Based on formula (12), we have:

$$
\varphi(p)=\frac{C_{1}}{C_{0}+C_{1}-2 \cdot\left(L_{0}+L_{1}\right)}
$$

For example of the $\mathrm{N}_{10}$, which is a factor of the supply chain risk, its cost and profit can be calculate from usual financial data. The prevent cost of $N_{10}$ is 451800 RMB. The interrupt cost of $N_{10}$ is 411100RMB. The risk obedient earnings of $N_{10}$ is 26300RMB. The opportunity cost of $\mathrm{N}_{10}$ is 44900RMB. That is: $\mathrm{C}_{0}=45.18, \mathrm{C}_{1}=41.11, \mathrm{~L}_{010}=2.63, \mathrm{~L}_{110}=4.49$.

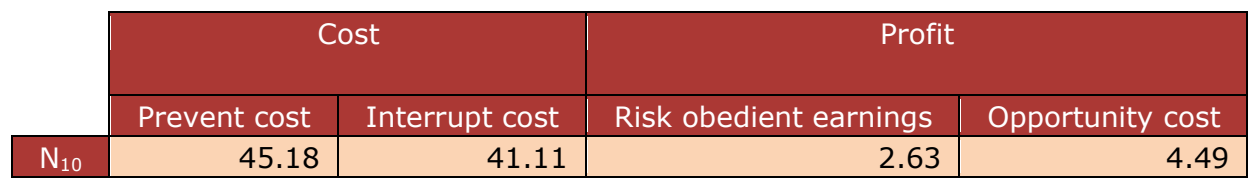

Table 3. Parameters Demonstration of $\mathrm{N}_{10}$

So, we can calculate: $\varphi\left(p^{*}\right)=0.57$

If $\mathrm{P}$ is subject to standard normal distribution, it can be seen that $\mathrm{P} *=0.7157$, this is the optimal evaluation to the risk of $\mathrm{N}_{10}$ by trade-off its cost and profit.

\begin{tabular}{|c|c|c|c|c|c|}
\hline \multirow{2}{*}{ Number } & \multicolumn{2}{|c|}{ Cost } & \multicolumn{2}{|c|}{ Profit } & \multirow{2}{*}{ Simulation results } \\
\hline & Prevent cost $\mathrm{C}_{0}$ & Interrupt cost $\mathrm{C}_{1}$ & Risk obedient earnings $L_{0}$ & Opportunity cost $\mathrm{L}_{1}$ & \\
\hline $\mathrm{N}_{1}$ & 65.89 & 42.79 & 2.71 & 9.73 & 0.51 \\
\hline $\mathrm{N}_{2}$ & 27.47 & 57.99 & 1.59 & 8.71 & 0.89 \\
\hline $\mathrm{N}_{3}$ & 79.29 & 75.66 & 2.09 & 6.23 & 0.55 \\
\hline $\mathrm{N}_{4}$ & 53.28 & 63.45 & 7.16 & 8.34 & 0.74 \\
\hline $\mathrm{N}_{5}$ & 26.03 & 2.90 & 7.87 & 5.67 & 1.57 \\
\hline$N_{6}$ & 98.02 & 1.45 & 5.10 & 0.66 & 0.02 \\
\hline $\mathrm{N}_{7}$ & 54.18 & 66.65 & 9.15 & 1.16 & 0.67 \\
\hline $\mathrm{N}_{8}$ & 58.07 & 14.35 & 1.52 & 5.44 & 0.25 \\
\hline $\mathrm{N}_{9}$ & 40.97 & 44.44 & 8.61 & 6.89 & 0.82 \\
\hline $\mathrm{N}_{10}$ & 97.80 & 55.38 & 7.94 & 2.58 & 0.42 \\
\hline $\mathrm{N}_{11}$ & 59.98 & 32.66 & 1.81 & 5.79 & 0.42 \\
\hline $\mathrm{N}_{12}$ & 62.97 & 27.96 & 1.33 & 7.22 & 0.38 \\
\hline $\mathrm{N}_{13}$ & 67.47 & 1.22 & 7.46 & 4.26 & 0.03 \\
\hline $\mathrm{N}_{14}$ & 12.02 & 11.41 & 1.21 & 2.61 & 0.72 \\
\hline $\mathrm{N}_{15}$ & 10.40 & 27.69 & 0.91 & 0.45 & 0.78 \\
\hline $\mathrm{N}_{16}$ & 68.34 & 33.09 & 9.18 & 6.06 & 0.47 \\
\hline $\mathrm{N}_{17}$ & 16.30 & 92.62 & 7.40 & 2.88 & 1.05 \\
\hline $\mathrm{N}_{18}$ & 40.31 & 33.71 & 2.69 & 9.59 & 0.68 \\
\hline
\end{tabular}

Table 4. Calculation-result 1 
We can assignment to the 18 factors in table 2, those are from $N_{1}$ to $N_{18}$, with the same methods of $N_{10}$. And Hypothesis $C_{0}, C_{1} \sim U[0,100], L_{0}, L_{1} \sim U[0,10]$. Using RAND function for 3 times, the simulation results are in table 4 , table 5 and table 6.

\begin{tabular}{|c|c|c|c|c|c|}
\hline \multirow{2}{*}{ Number } & \multicolumn{2}{|c|}{ Cost } & \multicolumn{2}{c|}{ Profit } & Simulation results \\
\cline { 2 - 5 } & Prevent cost $\mathrm{C}_{0}$ & Interrupt cost $\mathrm{C}_{1}$ & Risk obedient earnings $\mathrm{L}_{0}$ & Opportunity cost $\mathrm{L}_{1}$ & Sin \\
\hline $\mathrm{N}_{1}$ & 59.85 & 37.77 & 6.21 & 6.33 & 0.52 \\
\hline $\mathrm{N}_{2}$ & 98.21 & 23.96 & 8.61 & 5.08 & 0.25 \\
\hline $\mathrm{N}_{3}$ & 25.22 & 52.93 & 4.08 & 3.23 & 0.83 \\
\hline $\mathrm{N}_{4}$ & 24.48 & 81.27 & 0.01 & 1.23 & 0.79 \\
\hline $\mathrm{N}_{5}$ & 45.61 & 34.16 & 3.22 & 3.19 & 0.51 \\
\hline $\mathrm{N}_{6}$ & 19.74 & 28.79 & 2.35 & 1.08 & 0.69 \\
\hline $\mathrm{N}_{7}$ & 34.66 & 51.43 & 9.46 & 0.68 & 0.78 \\
\hline $\mathrm{N}_{8}$ & 55.05 & 26.02 & 5.76 & 0.43 & 0.38 \\
\hline $\mathrm{N}_{9}$ & 96.64 & 57.03 & 5.94 & 3.14 & 0.42 \\
\hline $\mathrm{N}_{10}$ & 10.88 & 27.94 & 0.36 & 6.92 & 1.15 \\
\hline $\mathrm{N}_{11}$ & 77.50 & 47.74 & 5.52 & 8.66 & 0.49 \\
\hline $\mathrm{N}_{12}$ & 13.07 & 78.24 & 8.95 & 4.60 & 1.22 \\
\hline $\mathrm{N}_{13}$ & 69.05 & 73.88 & 1.98 & 2.24 & 0.55 \\
\hline $\mathrm{N}_{14}$ & 70.15 & 32.14 & 3.45 & 6.19 & 0.39 \\
\hline $\mathrm{N}_{15}$ & 73.96 & 21.93 & 5.05 & 3.44 & 0.28 \\
\hline $\mathrm{N}_{16}$ & 71.01 & 7.70 & 8.78 & 3.35 & 0.14 \\
\hline $\mathrm{N}_{17}$ & 42.97 & 29.69 & 1.20 & 8.54 & 0.56 \\
\hline $\mathrm{N}_{18}$ & 90.25 & 61.82 & 3.04 & 3.23 & 0.44 \\
\hline
\end{tabular}

Table 5. Calculation-result 2

\begin{tabular}{|c|r|r|r|r|r|}
\hline \multirow{2}{*}{ Number } & \multicolumn{2}{|c|}{ Cost } & \multicolumn{2}{c|}{ Profit } & Simulation results \\
\cline { 2 - 5 } & Prevent cost $C_{0}$ & Interrupt cost $C_{1}$ & Risk obedient earnings $L_{0}$ & Opportunity cost $L_{1}$ & 3.02 \\
\hline$N_{1}$ & 66.24 & 89.88 & 5.43 & 0.65 \\
\hline$N_{2}$ & 47.07 & 6.02 & 2.28 & 1.92 & 0.13 \\
\hline$N_{3}$ & 92.68 & 4.57 & 1.85 & 4.78 & 0.05 \\
\hline$N_{4}$ & 80.23 & 52.41 & 4.54 & 3.47 & 0.45 \\
\hline$N_{5}$ & 37.71 & 73.70 & 0.54 & 1.49 & 0.69 \\
\hline$N_{6}$ & 36.41 & 16.33 & 6.75 & 3.10 & 0.49 \\
\hline$N_{7}$ & 68.68 & 0.65 & 8.10 & 9.95 & 0.02 \\
\hline$N_{8}$ & 88.89 & 66.55 & 5.29 & 7.02 & 0.51 \\
\hline$N_{9}$ & 75.87 & 79.98 & 1.93 & 1.31 & 0.54 \\
\hline$N_{10}$ & 4.93 & 26.58 & 5.28 & 2.75 & 1.72 \\
\hline$N_{11}$ & 32.94 & 48.28 & 5.63 & 4.77 & 0.80 \\
\hline$N_{12}$ & 51.61 & 83.35 & 8.46 & 2.77 & 0.74 \\
\hline$N_{13}$ & 72.52 & 69.17 & 4.85 & 7.49 & 0.59 \\
\hline$N_{14}$ & 97.08 & 60.50 & 8.55 & 9.64 & 0.50 \\
\hline$N_{15}$ & 49.02 & 84.91 & 1.77 & 10.00 & 0.77 \\
\hline$N_{16}$ & 47.71 & 68.60 & 3.26 & 0.63 & 0.63 \\
\hline$N_{17}$ & 17.37 & 86.94 & 2.28 & 4.75 & 0.96 \\
\hline$N_{18}$ & 83.86 & 43.84 & 9.43 & 4.56 & 0.44 \\
\hline
\end{tabular}

Table 6. Calculation-result 3

\section{Conclusions}

This paper builds a newsvendor model for supply chain disruption assessment, which applies the tradeoff idea of newsvendor to this model. This model considers both opportunity cost and disruption cost, between which is a cost-income principle tradeoff. When a risk's assessment is higher than optimum, disruption cost will descend whereas opportunity cost ascend; when the risk's assessment is lower than the optimal one, disruption cost will ascend while opportunity cost descend. Among which, the optimum is the "critical point" deducted by the disruption assessment in newsvendor model. The "critical point" can minimize the expectation loss of 
these both costs. At the same time, the two cost stand for two opposite attitudes and preferences towards risks. Opportunity cost is on behalf of risk averse; disruption cost stand for risk appetite. That can extend the traditional risk neutral newsvendor.

Simultaneously, this model can be also used to rank a series of risk events $N_{i}(i=1,2,3 \ldots)$ may happen in every link of a supply chain according to their importance. Pi* can represent the probability of risk $\mathrm{Ni}$, whose expectation loss is the least one. Taking another look at it, the lower $\mathrm{Pi}^{*}$ is, the more likely the risk event causing cost, the more attention should be paid, the more vital the risk event. In contrast, when $\mathrm{P}_{\mathrm{i}}^{*}$ is lower, the risk event is not that important than the former.

\section{References}

Anastasios X., Dimitrios, V., \& Eleftherios, I. (2012). Optimal newsvendor policies for dualsouring supply chains: A disruption risk management framework. Computers \& Operational Research, 39, 350-357. http://dx.doi.org/10.1016/j.cor.2011.04.010

Christopher S.T. (2006). Perspective in supply chain risk management. International Journal of Production Economics, 103, 451-488. http://dx.doi.org/10.1016/j.ijpe.2005.12.006

Ding, W., Liu K., \& He, G., (2003). Study on risk of supply chain. China Safety Science Journal, 13(4), 64-66.

Harland, C., Brenchley, R., \& Walker, H. (2003). Risk in supply networks. Journal in Purchasing and Supply Management, 9(2), 51-62. http://dx.doi.org/10.1016/S1478-4092(03)00004-9

Manuj, I., \& Mentzer, J. (2008). Global supply chain risk management. Journal of Business Logistics, 29(1), 133-155. http://dx.doi.org/10.1002/j.2158-1592.2008.tb00072.x

Meng, K. (2009). Comprehensive grey fuzzy evaluation on research on supply chain risk based on. The Friend of the Head, 58(10).

Qin, Y., Wang, R., Vakharia, A.J., Chen, Y., \& Seref, M.M.H. (2011). The newsvendor problem: Review and directions for future research. European Journal of Operational Research, 213, 361-374. http://dx.doi.org/10.1016/j.ejor.2010.11.024

Ritchie, B., \& Brindley, C. (2004). Risk characteristics of the supply chain-A contingency framework. Supply Chain Risk.

Wakolbinger, T. \& Cruz, J.M. (2011). Supply chain disruption risk management through strategic information acquisition and sharing and risk-sharing contracts. International Journal of Production Research, 49(13), 4063-4084. http://dx.doi.org/10.1080/00207543.2010.501550 
Werner, J., \& Peter K. (2011). Risk preferences of a news vendor with service and loss constraints. International Journal of Production Economics.

Werner, J., \& Peter, K. (2008). A newsvendor model with service and loss constraints. Jena Research Papers in Business and Economics.

Werner. J., \& Peter, K. (2007). Risk-averse and risk-taking newsvendors: A conditional expected value approach. Review of Management Science, 1(1), 93-110. http://dx.doi.org/10.1007/s11846-007-0005-7

Xu, M., \& Li, J. (2010). Optimal decision when balancing expected profit and confidention value-at-risk in newsvendor model. Journal of Systems Science \& Complexity, 23, 10541070. http://dx.doi.org/10.1007/s11424-010-7116-y

Zhang, S. (2011). Fortification models hedging disruption risks based on arborescent supply chain. Operations research and managment science, 20(1), 186-191.

Journal of Industrial Engineering and Management, 2013 (www.jiem.org)

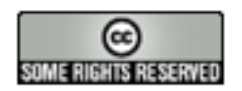

El artículo está con Reconocimiento-NoComercial 3.0 de Creative Commons. Puede copiarlo, distribuirlo y comunicarlo públicamente siempre que cite a su autor y a Intangible Capital. No lo utilice para fines comerciales. La licencia completa se puede consultar en http://creativecommons.org/licenses/by-nc/3.0/es/ 